\title{
Assessment and Forecast of Soil Formation under Irrigation in the Steppe Zone of Ukraine
}

\author{
F. N. Lisetskii ${ }^{a}$ and V. I. Pichura ${ }^{b}$ \\ ${ }^{a}$ Belgorod State National Research University, ul. Pobedy 85, Belgorod, 308015 Russia \\ e-mail: liset@bsu.edu.ru \\ ${ }^{b}$ Kherson State Agricultural University, ul. Rosa Luxemburg, 23, Kherson, 73006 Ukraine \\ e-mail:pichura@yandex.ru \\ Received October 7, 2015
}

\begin{abstract}
Simulation of changes in energy costs of soil formation during the period of irrigation reclamation in the steppe zone has been performed using Wavelets analysis. A method has been proposed for the evaluation of natural-anthropogenic soil-forming process with consideration for the contribution of irrigation water to the hydrothermal regime during the growing season and the prediction of soil evolution under the effect of changing climatic conditions for the area of irrigated agriculture.
\end{abstract}

Keywords: irrigation reclamation, steppe zone, soil formation, forecasting

DOI: $10.3103 / \mathrm{S} 1068367416020075$

\section{INTRODUCTION}

Steppe and dry-steppe landscapes were developed under adequate thermal but water-deficient conditions. From the generalized meteorological series (1900-2014), the annual precipitation is estimated at $400 \mathrm{~mm}$ and the mean annual air temperature is estimated at $9.8^{\circ} \mathrm{C}$. From the beginning of vegetation to the harvest of cereal crops, the probability of drought is $40 \%$ in the Black Sea region of dark chestnut soils and $30 \%$ in the chernozemic steppe subzones; the probability of years with intensive and very intensive hot winds is $40-90 \%$. The soil cover of agrolandscapes is diverse: ordinary and southern chernozems and dark chestnut soils in combination with solonetzic soils. The reserves of nutrients and their availability to plants, as well as the reserves of productive moisture, are controlled by the natural-climatic conditions of agrolandscapes (relief, hydrogeology, soil-climatic resources, etc.) [1]. The high degree of plowing of steppe and dry-steppe landscapes (65-75\%), the widespread development of irrigation, and the wind and precipitation patterns largely determine the active development of deflation and water erosion of soils, which results in the deterioration of their agrophysical and agrochemical statuses; a complex of problems is faced in irrigation reclamation, and new trends in soil-forming processes are coming up in the irrigation zone.

The development of new approaches to integrated estimates of the soil-forming potential of the climate having a prognostic potential is necessary for assessing the anthropogenic contribution of the irrigation reclamation of lands in the dry and dry-steppe zones [2].
The natural-anthropogenic soil-forming process on irrigated lands is characterized by accelerated and irreversible manifestations, while the results of the agrogenically controlled evolution of soils in old developed regions of unirrigated farming are revealed after hundreds of years [3].

The aim of this work was to estimate the dynamics and predict the evolution of pedogenesis in Kherson oblast, where agricultural lands occupy 1971000 ha $(69.2 \%)$, including 1778000 ha $(90.2 \%)$ of plowland. The area includes $20 \%$ of the irrigated land in Ukraine, which corresponds to 426800 ha, although only 285000 ha are in use.

\section{EXPERIMENTAL}

We used the methodology of bioenergetic approach [4], which allows simulating the scenarios of climatic impacts (through heat and moisture supply) expressed in energy equivalents on the evolution of soils in time. Earlier, the procedure of calculating the energy costs of soil formation $(Q)$ depending on climatic factors was improved at the development of this approach [5], and a model was proposed for the humus horizon thickness as a function of the $Q$ value and the content of the physical clay fraction in the parent rocks [6]. The radiation balance, the energy costs of soil formation $\left(Q, \mathrm{MJ} / \mathrm{m}^{2}\right)$, and the maximum thickness of the humus soil horizon $\left(H_{\mathrm{lim}}, \mathrm{mm}\right)$ as a function of $Q$ and the content of physical clay in the parent rocks $(P C, \%$; $<0.01 \mathrm{~mm}$ ) were calculated according to the reported procedures $[5,6]$. Data on the air temperature $\left(T,{ }^{\circ} \mathrm{C}\right)$ and total precipitation $(P, \mathrm{~mm})$ during the vegetation 


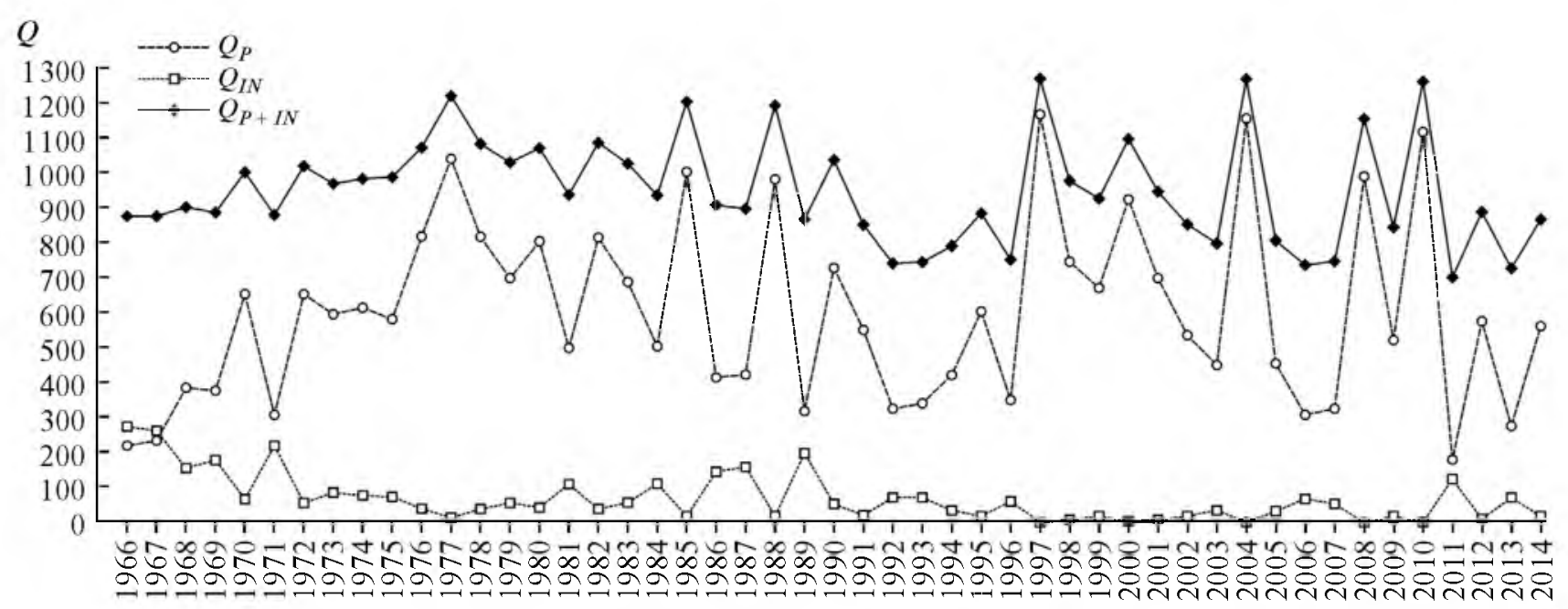

Fig. 1. Dynamics of the climatic and anthropogenic energy supply of soil formation under irrigation reclamation in the steppe zone of Ukraine (1966-2014): climatic $\left(Q_{P}, \mathrm{MJ} / \mathrm{m}^{2}\right)$, anthropogenic $\left(Q_{\mathrm{IR}}, \mathrm{MJ} / \mathrm{m}^{2}\right)$, and total $\left(Q_{P+\mathrm{IR}}, \mathrm{MJ} / \mathrm{m}^{2}\right)$ energies.

period were borrowed from eight meteorological stations of Kherson oblast. The appraisal period was determined by the duration of irrigated farming (1966-2014). Data of the Kherson Regional Department of Water Resources were used, which allowed revealing the spatial and temporal distribution features of irrigation water (IR, $\mathrm{mm}$ ) on the irrigated lands. Radar topographic survey was used to compose a digital relief model and assess the distribution of radiation balance $\left(R, \mathrm{MJ} / \mathrm{m}^{2}\right)$ over the area. The expansion of the initial series $Q$ for the determination of the trend $(T)$ and the low-frequency (approximating, $A$ ) and high-frequency $(D)$ signals was performed using the Wavelets transform of the Meyer function of the fifth order $[7,8]$, which ensured the conservation of the initial signal energy by $96.17 \%$. For the simulation and prediction of pedogenesis evolution on the irrigated lands, we used a theoretical model including the sum of sinusoids in the form

$$
f(x)=\sum_{i=1}^{N}\left(a_{i} \sin \left(b_{i} t+c_{i}\right)\right),
$$

where $x$ is the value of the studied parameter; $a$ is the amplitude of variation; $b$ is frequency of variation; $c$ is the phase (intercept), which is constant for each sinusoidal wave in time; $t$ is the discrete time value at moment $i$; and $n$ is the number of the series members or the retrospective time projection.

The adequacy of model (1) was estimated using prediction reliability criteria $[9,10]$. Spatial-temporal analysis, simulation, and prediction were performed using Statistica Advanced + QC for Windows v. $10 \mathrm{Ru}$, MathWorks Matlab 7.9 R2009b, and ArcGIS 10.1 software.

\section{RESULTS AND DISCUSSION}

The main climatic parameters determining the energy costs of soil formation $(Q)$ include the sum of air temperatures $>10^{\circ} \mathrm{C}$ and the total precipitation during the vegetation period (April-October). A positive trend in temperature changes during the vegetation was noted for 48 years of observations, an extremum of which corresponds to the early 21 st century (with a periodicity of $8-9$ years). The period of observations (1966-2014) can be subdivided into the periods of air temperature $\left(T,{ }^{\circ} \mathrm{C}\right)$ formation under stable (19661996): $\bar{T}=16.54 \pm 0.16 ; V=5.4 \% ; T=-0.168 \ln (t)+$ $16.96 ; r=0.16)$ and unstable $(1997-2014): \bar{T}=18.12 \pm$ $\left.0.31 ; V=7.4 \% ; T=16.403 e^{0.0102 t} ; r=0.76\right)$ conditions. The increase of air temperature and radiation balance implies an increase of irrigation rate (IR), but the increase of precipitation according to the trendcyclic (11 years) scenario determines the development of a positive trend in the energy costs of soil formation $\left(Q_{P}\right)$, which resulted, under difficult social-economic conditions (significant increase in the cost of irrigation water) of the last 25 years, in the reduction of energy consumption for irrigation reclamation $\left(Q_{\mathrm{IR}}\right)$ by 2.7 times: from 147.6 (1966-1990) to $55.4 \mathrm{MJ} / \mathrm{m}^{2}$ (1991-2014) (Fig. 1).

The dynamics of irrigation rate as a function of total precipitation during the vegetation period is described by an exponential equation. The form of the relationship varies among the separate periods: in $1966-1989, \mathrm{IR}=20224 P^{-0.9248} ; r=0.795 ; r^{2}=0.632$; in $1990-2014, \mathrm{IR}=20379 P^{-0.9888} ; r=0.801 ; r^{2}=$ 0.652 . In $1966-2014$, the total precipitation during the vegetation period in Kherson oblast increased 


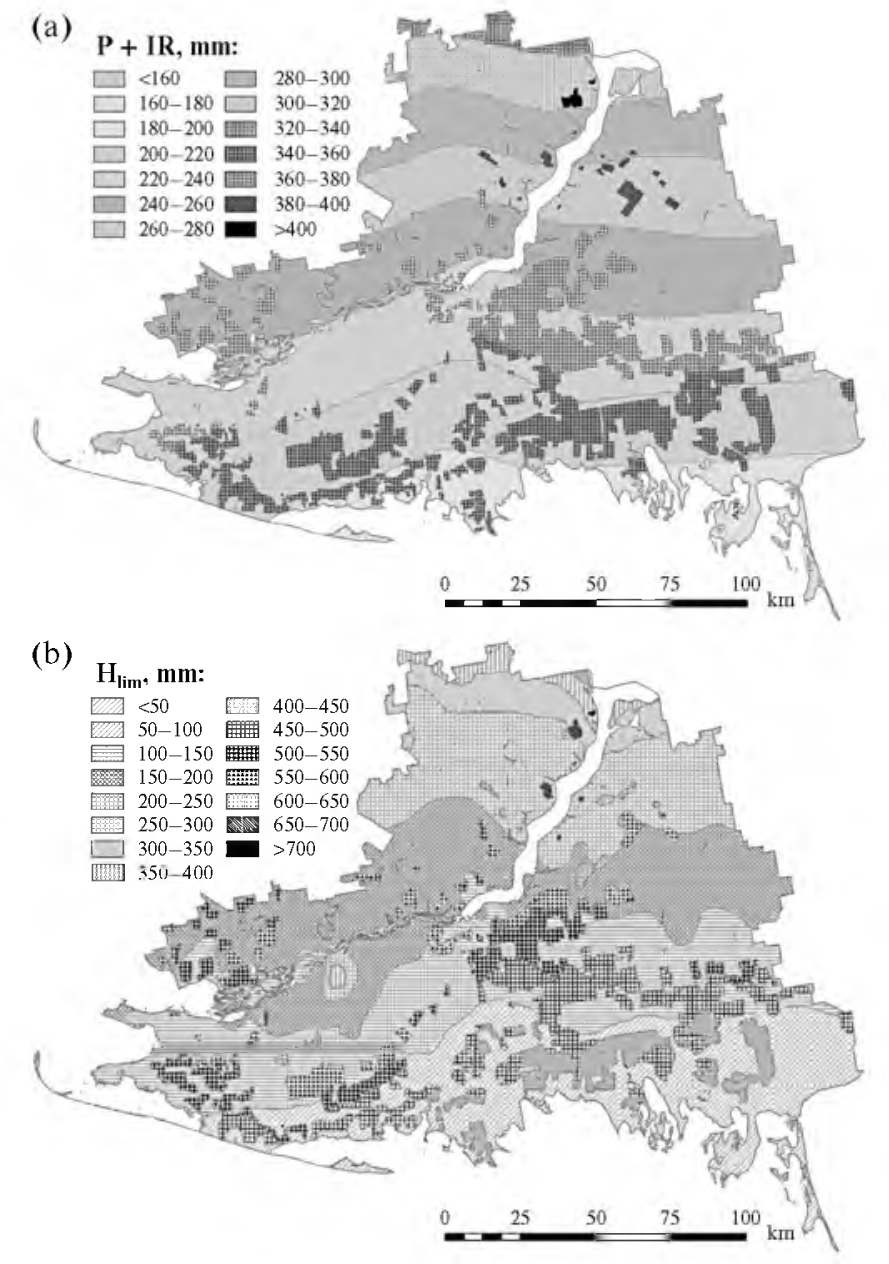

Fig. 2. Distribution of water supply conditions during the vegetation period and the soil-formation potential on irrigated and unirrigated lands of Kherson oblast: (a) total water supply: sum of precipitation $(P, \mathrm{~mm})$ and irrigation rate (IR, mm); (b) calculated maximum thickness of the humus soil horizon $\left(H_{1 \mathrm{im}}, \mathrm{mm}\right)$.

from 155 to $330 \mathrm{~mm}$ when going from south to north. The total water supply $(P+$ IR) on the irrigated lands was $345-410 \mathrm{~mm}$ (Fig. la), which ensured the increase in the energy costs of soil formation $\left(Q_{P+\mathrm{IR}}\right)$ during the vegetation period by $335 \mathrm{MJ} / \mathrm{m}^{2}$ (to $850 \mathrm{MJ} / \mathrm{m}^{2}$ ) on average. The total energy costs of soil formation in the area during the vegetation are differentiated: $790-910 \mathrm{MJ} / \mathrm{m}^{2}$ on the irrigated lands and $265-765 \mathrm{MJ} / \mathrm{m}^{2}$ on the nonirrigated lands.

Earlier [6], a relationship of the maximum thickness of the humus soil horizon ( $\left.H_{\mathrm{lim}}\right)$ with the energy costs of soil formation $(Q)$ and the proportion of physical clay $(<0.01 \mathrm{~mm}, P C, \%)$ was derived in the form

$$
H_{\mathrm{lim}}=\frac{3914.6 P C^{-0.19}}{1+e^{(5.346-0.00523 Q)}}
$$

The estimation of changes in hydrothermal conditions from Eq. (2) makes it possible to obtain the potential thickness of the humus soil horizon $\left(H_{\mathrm{lim}}\right)$. This value varies in a wide range (Fig. 2b) from an average of $238 \mathrm{~mm}(45-430 \mathrm{~mm})$ on the nonirrigated lands to $605 \mathrm{~mm}(410-800 \mathrm{~mm})$ on the irrigated lands. At the northern distribution limit of low-humus ordinary and southern chernozems (humus content $G=$ $2.60-3.85 \%$ ), the value of $H_{\mathrm{lm}}$ can reach $250-430 \mathrm{~mm}$ on the nonirrigated lands and $630-800 \mathrm{~mm}$ on the irrigated lands; the corresponding values are 110-250 and $480-630 \mathrm{~mm}$ in the southern chernozem zone $(G=$ $2.00-3.30 \%$ ), as well as $100-160$ and $430-550 \mathrm{~mm}$, respectively, in the zone of dark-chestnut soils $(G=$ $1.75-3.00 \%)$. The southern part of the area is occupied by chestnut and meadow-chestnut solonetzic soils $(G=1.00-2.6 \%)$ with a predicted $H_{\lim }$ value of 410-550 $\mathrm{mm}$.

According to the spatial distribution models for the $Q$ and $H_{\text {lim }}$ values, the most favorable conditions for soil formation are created in the zone of ordinary and southern chernozems. However, the intensive development of irrigation (1970-1989) resulted in the leaching of humus to the lower horizons and the decrease of its content $(G, \%)$ in the $0-40 \mathrm{~cm}$ layer 

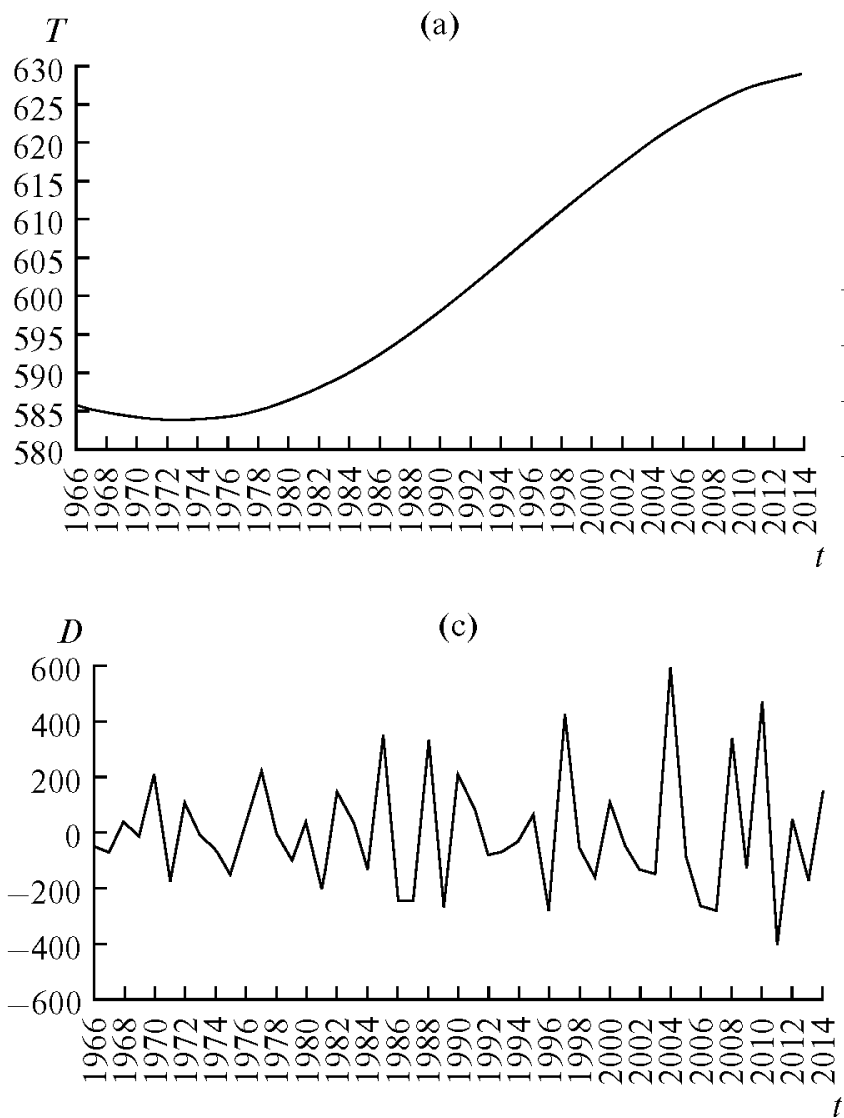

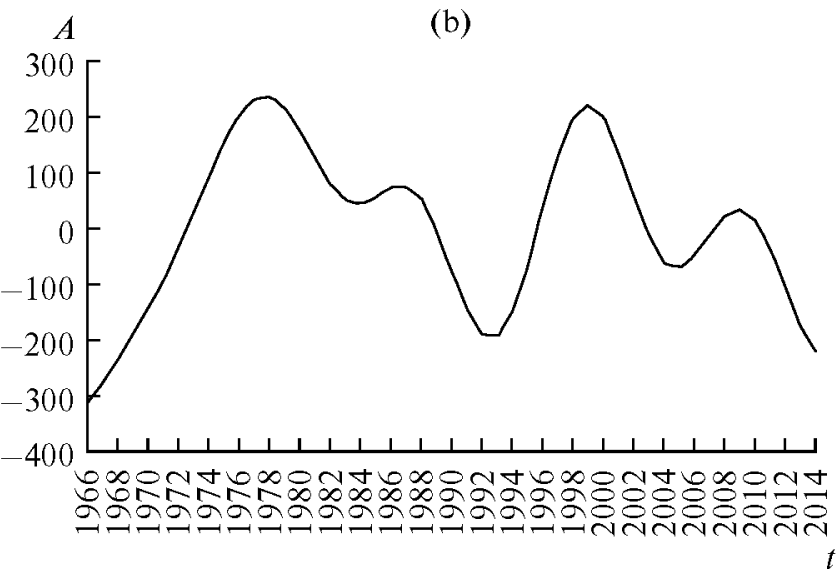

(d)

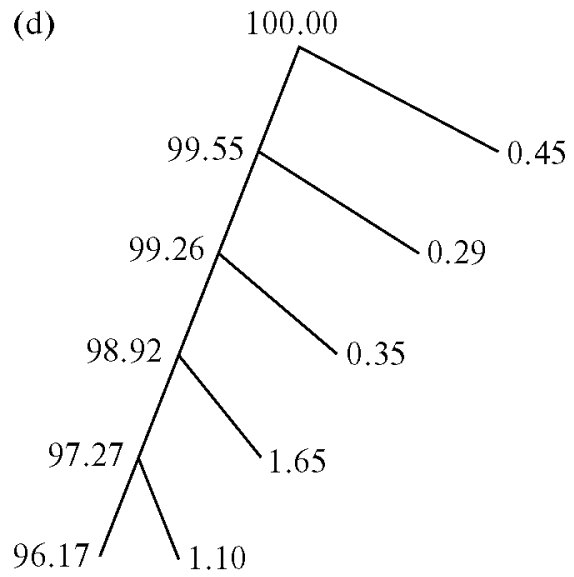

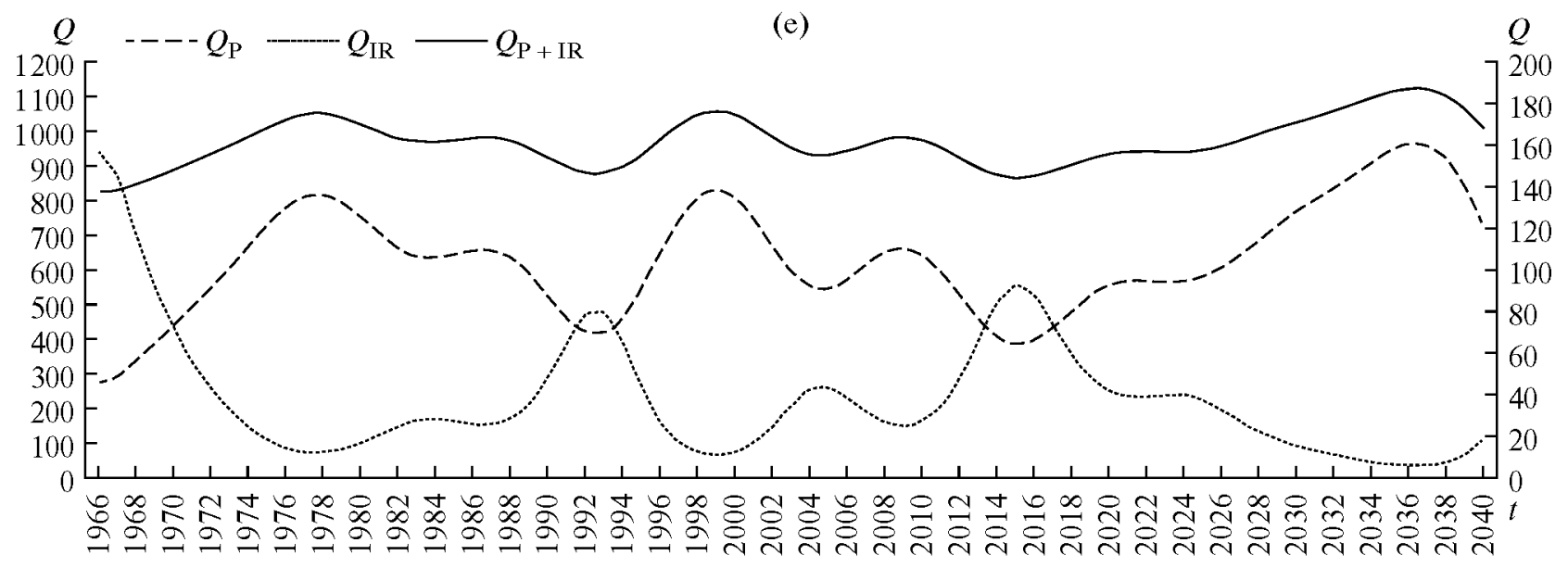

Fig. 3. Decomposition, dynamics, and prediction of the energy costs of soil formation during the vegetation period up to 2040: (a) trend component (T); (b) low-frequency component $(A)$; (c) high-frequency component ( $D$, white noise); (d) Wavelets tree for the initial signal energy conservation; (e) dynamics and prognosis of energy costs $f(Q)=f(T)+f(A)$ (left axis, $Q_{P}, Q_{P+\mathrm{IR}}$; right axis, $\left.Q_{\mathrm{IR}}\right)$.

from 2.56 to $2.20 \%$. The period of $1990-2014$ was characterized by a stable irrigation reclamation load and the manifestation of dehumification with time $(t)$ $(G=-0.0061 t+2.2914)$ with an insignificant variation $\left(C_{V}=0.03 \%\right)$. Therefore, the stabilization of soil degradation processes, primarily on the irrigated lands, can be ensured by the adequate input of harvest residues and organic fertilizers into the plow horizon; the decrease in the share of row crops; the increase in proportions of perennial grasses and field crop rotations; the reduction of unbalanced mineral fertilization (especially the application of physiologically acid 
fertilizers); the complete use of plant residues as fertilizers; the reduction of water erosion, including the scientifically based optimization of irrigation rates; etc.

To predict the evolution of pedogenesis under irrigation reclamation, the Wavelets transform of the initial series of climatic energy costs $\left(Q_{P}\right)$ was performed. The decomposition of harmonic variations of different levels separated the trend ( $T_{P}$, Fig. 3a), low-frequency
$\left(A_{P}\right.$, Fig. 3b), and high-frequency $\left(D_{P}\right.$, Fig. 3c) components. The function of the five-level decomposition of the time series has the following form: $f\left(Q_{P}\right)=f\left(T_{P}\right)+$ $f\left(A_{P}\right)+f\left(D_{P}\right)$. The Wavelets tree of the five-level decomposition coefficients and the stepwise preservation of the initial signal time series is presented in Fig. $3 \mathrm{~d}$. The functions of the separate components are presented as sums of sinusoids in system (3).

$$
Q_{P}=\left\{\begin{array}{l}
f(T)=1453 \sin (0.02291 t+81.96)+869.1 \sin (0.03151 t+200.1), \quad r=0.99, \quad r^{2}=0.98 \\
f(A)=674.5 \sin (0.1892 t+143.4)+73.31 \sin (0.5141 t+17.21)+644.5 \sin (0.1754 t-89.85) \\
+63.26 \sin (0.6238 t+61.68)+60.47 \sin (0.3115 t+158), \quad r=0.97, \quad r^{2}=0.94 \\
f(D)=1113 \sin (2.912 t-63.02)+1110 \sin (2.918 t+185.8)+94.87 \sin (2.075 t+41.05) \\
+85.39 \sin (1.933 t+60.24)+67.27 \sin (2.662 t-88.16)+113.4 \sin (2.496 t-20.4) \\
+67.1 \sin (0.9913 t+114.7), \quad r=0.79, \quad r^{2}=0.63
\end{array}\right.
$$

The system of functions (3) provides a practical opportunity for the long-term (from the trend component $f(T)$ ), medium-term (with account for the lowfrequency component $f(T)+f(A)$ ), and short-term (with account for the high-frequency component $f(T)$ $+f(A)+f(D))$ prognoses of the energy costs of soil formation with a high degree of certainty if the current trends of climatic changes in the steppe zone will continue.

The reliability of temporal simulation with account for the standard error of the input data was $94.97 \%$ for the trend component, $84.07 \%$ for the low-frequency component, and $59.02 \%$ for the high-frequency component. The long-term prognosis for 26 years (20152040) was performed from the trend and low-frequency components $(f(Q)=f(T)+f(A))$; the reliability of simulation was estimated at $90 \%$ (Fig. 3e).

The results of prediction suggest an increase in the natural energy costs of soil formation $\left(Q_{P}\right)$ to 2040 by $80 \mathrm{MJ} / \mathrm{m}^{2}$ at the established trends of climate changes in the steppe zone. Given an average decrease in the irrigation energy $\left(Q_{\mathrm{IR}}\right)$ by 1.4 times, this value will ensure a stable increase in the total energy of naturalanthropogenic soil formation $\left(Q_{P+\mathrm{IR}}\right)$ by $38 \mathrm{MJ} / \mathrm{m}^{2}$ on average. This can slow down the development of soil degradations revealed to the present.

\section{REFERENCES}

1. Pichura, V.I., Larchenko, O.V., Domaratsky, A., and Breus, D.S., Spatial assessment of the suitability of agricultural lands for growing and design of grain harvest using GIS technologies, Uch. Zap. Orlov. Gos.
Univ., Ser. Estestv. Tekh. Med. Nauki, 2013, no. 3, pp. 357-362.

2. Pichura, V.I. and Breus, D.S., The basin approach in the study of spatial distribution anthropogenic pressure with irrigation land reclamation of the dry steppe zone, Biogeosyst. Tech., 2015, vol. 3, pp. 89-100.

3. Lisetskii, F, Stolba, V., and Marinina, O., Indicators of agricultural soil genesis under varying conditions of land use, Steppe Crimea, Geoderma, 2015, vol. 239 240, pp. 304-316.

4. Volobuev, V.R., Vvedenie v energetiku pochvoobrazovaniya (Introduction to Soil Formation Energetics), Moscow: Nauka, 1974.

5. Lisetskii, F. and Chepelev, O.A., Climatic conditionality of soil formation in the Central Black Earth Region, Vestn. VGU, Ser. Geogr. Geoekol., 2003, no. 2, pp. 1523.

6. Lisetskii, F. and Chepelev, O., Quantitative substantiation of pedogenesis model key components, Adv. Environ. Biol., 2014, vol. 8, no. 4, pp. 996-1000.

7. Mayer, Y., Wavelets, generalized white noise and fractional: The synthesis of fractional brownian motion, J. Fourier Anal. Appl., 1995, no. 5 (5), pp. 465-494.

8. Yakovlev, A.N., Vvedenie $v$ veivlet-preobrazovaniya (Introduction to Wavelet Transformation), Novosibirsk: Izd. NGTU, 2003.

9. Pichura, V.I., The space-time forecasting of changes in the parameters of agrochemical indicators of reclaimed soils using GIS and neurotechnologies, Agrokhim. Gruntoznavstvo, 2012, no. 78, pp. 87-95.

10. Pichura, V.I., Pilipenko, Yu.V., Lisetskiy, F.N., and Dovbysh, O.E., Forecasting of hydrochemichal regime of the Lower Dnieper section using neurotechnologies, Hydrobiol. J., 2015, vol. 51, no. 3, pp. 100-110.

Translated by K. Pankratova 